\title{
Adaptive Zone-1 Setting Following Structural and Operational Changes in Power System
}

\author{
Subhadeep Paladhi, Student Member, IEEE and Ashok Kumar Pradhan, Senior Member, IEEE
}

\begin{abstract}
Change in network structure or operating condition in a power system affects the impedance as calculated by distance relay during fault. Such changes may lead to malfunction of distance relay at times. In this paper, an adaptive distance relay setting method using local data is proposed to prevent zone-1 malfunction following structural and operational changes. The performance of proposed adaptive setting method is tested on 39-bus New England system and a generic 12-bus power system using PSCAD/EMTDC simulation data and a comparative assessment is also provided.
\end{abstract}

Index Terms-Distance Relay, Adaptive Relaying, Numerical Protection, Structural Change, Power System Faults

\section{INTRODUCTION}

$\mathbf{R}$ EPORTS on recent blackouts ask for revamping existing schemes for transmission network protection [1]-[3]. Distance relaying is the common method for both primary and backup protection of transmission lines. Though a distance relay is set to protect a line for all types of fault, a large scale disturbance, like segregation of network, line tripping and bulk load/generation switching etc. affects relay operation and leads to its malfunction at times [4]-[7]. Power swing and load encroachment are considered as important issues leading to distance relay malfunction during such changes. To avoid unwanted line tripping during such situations, different blocking techniques are available for distance relaying [8]-[12]. The vulnerable points in a power system network prone to relay maloperation during such situations can be identified using different strategies such as system integrity protection scheme (SIPS), reachability analysis, superimposed technique, breakpoint determination etc. [4]-[7], [12]-[17]. These methods use wide area measurement system (WAMS) data with information of network topology. Such WAMS based approaches have been proposed for improvement in performance of zone-2 and zone-3, but not suitable to zone-1 due to latency issue.

The occurrence of any structural and operational changes in an interconnected power system modulates the voltage and power and results in change of the seen impedance of a distance relay significantly, particularly for high resistance faults [7], [16]-[20]. To compensate the effect of fault resistance in the presence of remote infeed, adaptive distance relay setting schemes have been proposed [20]-[25]. A zero sequence component based adaptive mho relay setting has

The work is supported in part by the Department of Science and Technology, New Delhi, India, under Grant DST/RCUK/SEGES/2012/02(G). The authors are with the Department of Electrical Engineering, Indian Institute of Technology, Kharagpur 721302, India (e-mail: paladhisubha_ee@iitkgp.ac.in; akpradhan@ee.iitkgp.ernet.in). been presented in [20]. The method is accurate in handling fault resistance but neglects the system impedances on both sides of the protected line. An adaptive distance protection is proposed in [21] calculating the voltage drop between relaying point and fault point considering fault resistance. An adaptive impedance relay based on composite polarizing voltage has been presented in [22], along with a blocking scheme to accommodate the inphase problem associated with high resistance faults. An adaptive setting method based on sequence components has been presented in [23]. A phase coordinate based fault resistance estimation scheme has been used for the distance relaying scheme in [24]. An adaptive mho relay setting using fault and prefault voltages as polarized quantities is proposed in [25]. These approaches consider the equivalent systems on both sides of protected line to remain constant, which may not be correct for a dynamic power system. The distance relay setting approaches presented in [18], [19] compensate the effect of high fault resistance under different loading conditions using artificial neural network approach which requires large number of training data. To obtain sufficient training sets for real power systems is difficult. Some of the available distance relays apply different relay setting techniques for protecting transmission lines for different source impedance ratio (SIR) situations [26]-[35]. Such relays with multiple settings for different SIRs cannot change the settings instantaneously under dynamic system conditions which is a requirement for zone-1 protection. These methods with predefined settings for different SIRs do not provide enough flexibility particularly for high resistance fault detection.

In this work an adaptive relay setting scheme is proposed to prevent zone-1 malfunction following structural or operational change in a power system. Proposed scheme uses a fixed zone1 setting followed by an adaptive setting with a delay of 2 cycles following a fault detection. This will avoid unintentional operation of the backup protection for a zone-1 fault during such a changed situation. The parameters required for the adaptive setting are calculated using local data available to the relay. Proposed scheme is tested using PSCAD/EMTDC simulation data for 39-bus New England system and a generic 12-bus power system. Comparative assessment shows the strength of the method.

\section{ISSUES ON Distance RELAY FOLLOWING Structural AND OPERATIONAL CHANGES}

Figure 1 shows a transmission network protected by stepped distance relaying scheme, where zone- 1 covers up to $80 \%$ of 
the line section and zone- 2 up to $50 \%$ of the shortest line section connected to the remote bus. The equivalent systems on the relay and the remote ends of transmission line in an interconnected power system are termed as local grid and remote grid respectively. The two grids consist of several subsystems interconnected with each other as shown in Fig. 1. The distance relays in the protection scheme are considered with quadrilateral characteristics to cover fault resistance up to $100 \Omega$.

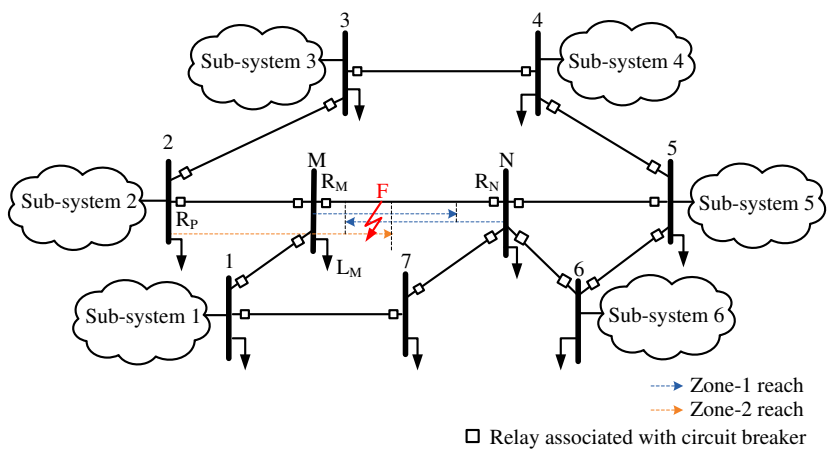

Fig. 1. Transmission system protected by stepped distance scheme

Figure 2 shows the equivalent diagram of the system shown in Fig. 1 while considering the protection of line MN. $E_{L}$ and $E_{R}$ are the internal voltages of equivalent sources at local and remote grid respectively. Similarly, $Z_{L M}$ and $Z_{N R}$ are the equivalent impedances for the two grids. The normal power flow direction in the system is from $\mathrm{M}$ to $\mathrm{N}$ (local grid to remote grid) as marked in the figure. The relation between the internal voltages of the two sides during prefault condition can be

$$
E_{R}=\left(\rho e^{-j \delta}\right) E_{L}
$$

where, $\rho$ and $\delta$ are the magnitude and phase of the ratio of internal voltages of local to remote grid respectively.

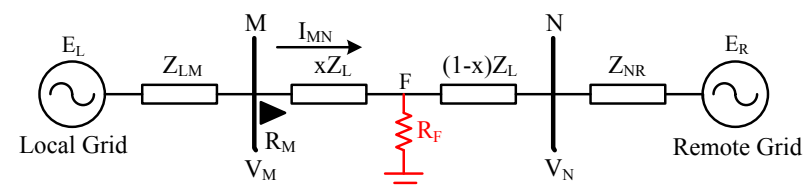

Fig. 2. Equivalent model for a fault in line $\mathrm{MN}$

The apparent impedance calculated by the distance relay $R_{M}$, for a line-to-ground fault is given by [17]

$$
Z_{a p p}=x Z_{1 L}+\Delta Z
$$

where $x$ is per unit fault distance, $Z_{1 L}$ is positive sequence line impedance.

$\Delta Z$ is the impedance correction factor and is related as (refer to Appendix I)

$$
\Delta Z=\frac{C_{R_{F}}}{\left(C_{e q}+C_{R_{F}}\right) C_{\rho \delta}+2 C_{12}+C_{0}\left(1+K_{0}\right)}
$$

where $C_{R_{F}}, C_{e q}, C_{\rho \delta}, C_{12}$ and $C_{0}$ are the current distribution factors due to fault resistance $\left(R_{F}\right)$, grid equivalent impedances, parameters associated with the ratio of internal voltages of local to remote grid $(\rho, \delta)$, system positive and zero sequence impedances respectively, as defined in Appendix I. $K_{0}$ is the zero sequence compensating factor of the line. The subscripts 0,1 and 2 represent for zero, positive and negative sequence components respectively. Thus $\Delta Z$ is a function of $\left(Z_{L}, Z_{L M}, Z_{N R}, \rho, \delta, R_{F}\right.$ and $\left.x\right)$, of which $Z_{L M}, Z_{N R}, \rho$ and $\delta$ are not considered for conventional relay setting approach. In a dynamic power system, $Z_{L M}$ for a relay may be affected significantly for any structural change in the network such as nearby line tripping, islanding etc. On the otherhand, $\rho$ and $\delta$ vary significantly for operational changes in the system such as generation or load switching, operation of FACTS devices etc. For different structural and operational scenarios, the zone-1 quadrilateral characteristics considering $R_{F}=100 \Omega$ calculated for relay $R_{\mathrm{M}}$ in the system of Fig. 2 are shown in Fig. 3. Large variation in the characteristics for different system conditions asks for an adaptive relay setting to avoid possible relay malfunction.

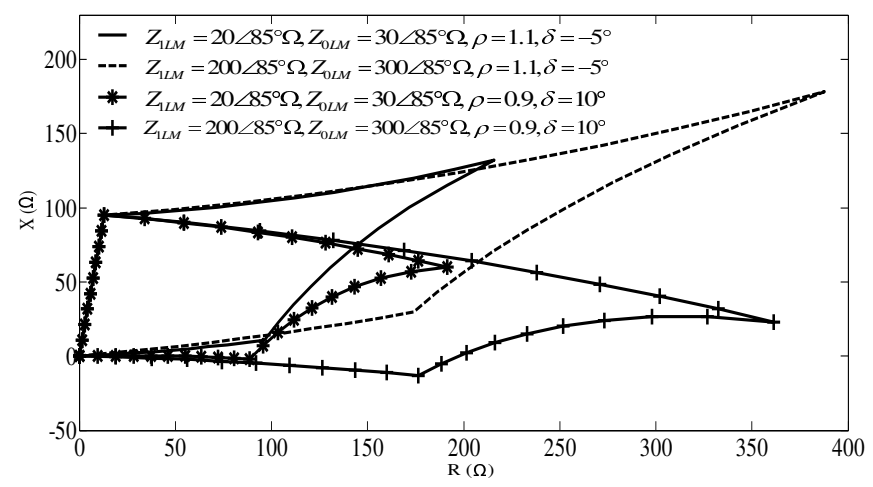

Fig. 3. Zone1 trip boundaries for different system conditions

A fault in line section $\mathrm{MN}$ at $\mathrm{F}$ at a distance of $40 \%$ from bus $M$ is in zone- 1 for relays $R_{M}$ and $R_{N}$ and in zone- 2 of $R_{P}$ as shown in Fig. 1. A line-to-ground fault at the same location following the disconnection of sub-system 1 from bus $M$ with a fault resistance of $90 \Omega$, becomes undetectable by zone-1 of relay $R_{M}$ and is shown in Fig. 4a. This is because of change in local grid equivalent impedance for the relay at bus $M$. Further the structural change affecting the remote bus relays $R_{N}$ and $R_{P}$ which detects the fault in their zone-1 and zone-2 properly (explained in Section III). The performances of the relays in identifying the fault during the situation are shown in Fig. $4 \mathrm{~b}$ and Fig. $4 \mathrm{c}$ respectively. This creates an unintentional outage of load $\mathrm{L}_{\mathrm{M}}$. Such relay malfunction, due to the effect of structural change in the network on seen impedance of the distance relay, hampers the reliability of the system. Such situations are also observed for operational changes in the power system such as bulk load/generator switching, distributed generation in the system with intermittency, dynamic operation of FACTS devices etc. (detailed in Section V). Thus there is a need for zone-1 adaptive setting for distance relay which may see significant structural or operational changes of the system. 


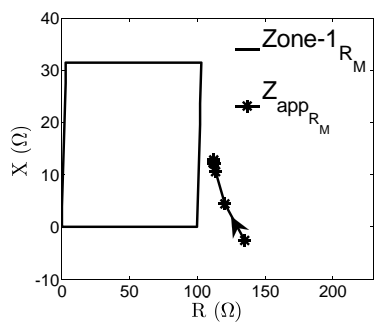

(a)

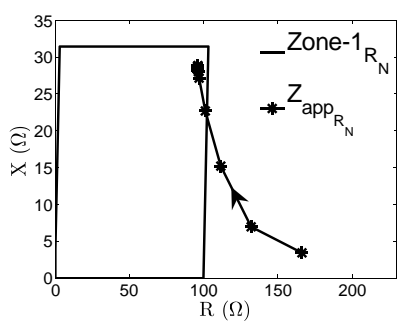

(b)

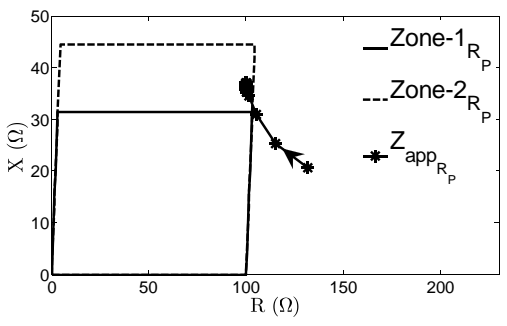

(c)

Fig. 4. Performance of relays following a structural change (a) for $R_{M}$, (b) for $R_{N}$ and (c) for $R_{P}$ relay

\section{Determination of Relay Setting Parameters}

To compensate for $\Delta Z$ and set the relay properly, it requires the parameters in (3) to be determined as described below.

\section{A. Determination of Equivalent Impedance of Local Grid}

Presence of $Z_{L M}$ in the current distribution factors (refer to Appendix I) shows its significance in zone-1 trip boundary computation. $Z_{L M}$ can be accurately determined applying superimposed technique [36] using the voltage and current measurements at relay point.

From the prefault and fault data, the incremental voltage and current at bus $\mathrm{M}$ can be obtained as

$$
\begin{gathered}
\Delta V_{M}=V_{M F}-V_{M p r e} \\
\Delta I_{M}=I_{M F}-I_{M p r e}
\end{gathered}
$$

where $\Delta V_{M}$ and $\Delta I_{M}$ represent the incremental voltage and current at bus M. Subscripts F and pre refer to the fault and prefault quantities respectively.

Fig. 5 shows the sequence network for the system of Fig. 2 with phase-A-to-ground fault. $V_{A F_{\text {pre }}}$ is the prefault phase A voltage at fault point. The incremental current and voltage for phase- $\mathrm{A}$ at bus $\mathrm{M}$ can be expressed as,

$$
\begin{aligned}
\Delta I_{A M}= & C_{12} \Delta I_{1 F}+C_{12} \Delta I_{2 F}+C_{0} \Delta I_{0 F} \\
\Delta V_{A M}= & -\left(C_{12} Z_{1 L M} \Delta I_{1 F}+C_{12} Z_{2 L M} \Delta I_{2 F}\right. \\
& \left.+C_{0} Z_{0 L M} \Delta I_{0 F}\right)
\end{aligned}
$$

The current distribution factors $C_{12}$ and $C_{0}$ for the situation are defined in Appendix I.

The incremental voltage and current component for a sequence component provides the incremental sequence impedance [36] as in (8).

$$
\Delta Z_{1 M}=\frac{\Delta V_{1 M}}{\Delta I_{1 M}}
$$

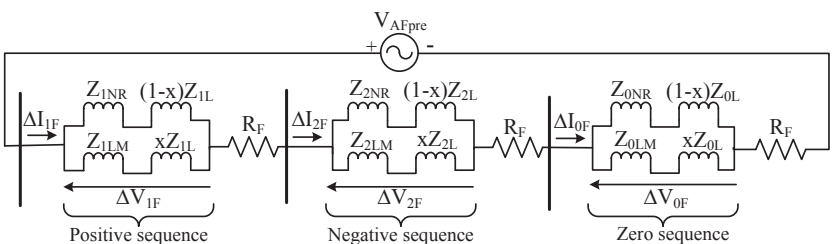

Fig. 5. Sequence networks for line-to-ground fault in the system

where, $\Delta I_{1 M}=C_{12} \Delta I_{1 F}$, and $\Delta V_{1 M}=-C_{12} Z_{1 L M} \Delta I_{1 F}$.

Substitution of these incremental voltage and current values in (8) provides the positive sequence impedance of local grid $\left(Z_{1 L M}\right)$ as follows:

$$
Z_{1 L M}=-\Delta Z_{1 M}
$$

Similarly, $Z_{0 L M}$ can also be determined as in (10).

$$
Z_{0 L M}=-\Delta Z_{0 M}
$$

\section{B. Determination of Equivalent Impedance of Remote Grid}

The remote grid sequence impedances can be determined performing superimposed technique at remote bus $\mathrm{N}$ as follows:

$$
\begin{aligned}
& Z_{1 N R}=-\Delta Z_{1 N} \\
& Z_{0 N R}=-\Delta Z_{0 N}
\end{aligned}
$$

Presence of equivalent sequence impedances of remote grid $\left(Z_{1 N R}\right.$ and $\left.Z_{0 N R}\right)$ in both numerator and denominator in current distribution factors $C_{12}$ and $C_{0}$ (refer to (20) and (21) in Appendix I) indicate negligible effect on $\Delta Z$ with the change in these parameters. The values determined at the initial stage of relay installation can be considered as fixed values for the relay operation in any condition. In case there is a system upgrade, the corresponding equivalent source impedance at the remote end should be taken into consideration in the proposed method.

\section{Determination of Internal Voltage Ratio of Local Grid to Remote Grid}

The raio of equivalent internal voltages of local grid to remote grid is determined during prefault condition as follows:

$$
\begin{gathered}
E_{1 L}=V_{1 M p r e}+I_{1 M p r e} Z_{1 L M} \\
E_{1 R}=V_{1 M p r e}-I_{1 M p r e}\left(Z_{1 L}+Z_{1 N R}\right)
\end{gathered}
$$

$\rho$ and $\delta$ as in (1) can be obtained from the ratio of the above determined voltages.

Using the above parameters values, the quadrilateral characteristic of a distance relay can be set accurately [17] for a line-to-ground fault. The same approach can be extended for other types of faults using appropriate relations for apparent impedance calculation as in [37]. 


\section{Issue with Determination of Adaptive setting Parameters}

Capacitive voltage transformer (CVT) transient following fault inception creates problem in accurate voltage phasor estimation, which is important for zone-1 decision. The transient period remains for 2 cycles following fault inception [38]. This restricts instantaneous zone-1 fixed setting reach to be maximum $67 \%$ [39]. To have a better zone-1 performance in the proposed method (as enumerated in section IV) a fixed setting of $67 \%$ reach and a adaptive setting of $80 \%$ reach with a delay of 2 cycles following a fault inception are proposed.

\section{Proposed Adaptive Zone-1 Setting}

From the above discussion it is observed that seen impedance of distance relay is significantly affected for structural and operational changes in the power system and identification of zone- 1 fault properly in such a situation is much important. For a better solution to zone-1 protection issue, an adaptive distance relay setting scheme is proposed with different steps as provided in Fig. 6. Proposed scheme consists

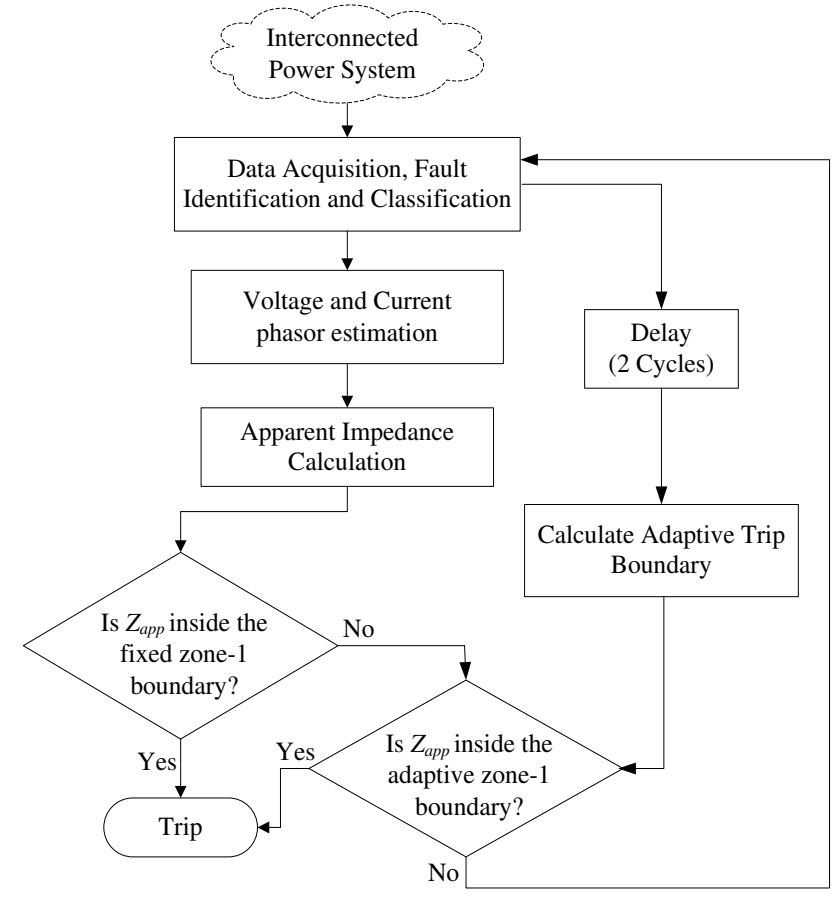

Fig. 6. Flowdiagram for the adaptive relay setting scheme

of a delayed adaptive setting besides a fixed reduced reach zone-1 setting and is shown in Fig. 7. The fixed setting is same as the conventional zone-1 setting with a reach reduced to $67 \%$ of line impedance [39] and the adaptive one with a setting based on present system condition and the usual zone-1 reach of $80 \%$. The distance relay calculates the apparent impedance $\left(Z_{a p p}\right)$ and in case of $Z_{a p p}$ is inside the fixed boundary, it takes the trip decision instantaneously. Otherwise the relay waits for 2 cycles following fault inception and computes the required parameters to derive the required adaptive setting. Such a delay overcomes the uncertainty in measurements due to CVT transient. The relay re-checks the apparent impedance with its adaptive setting after 2 cycles following fault inception

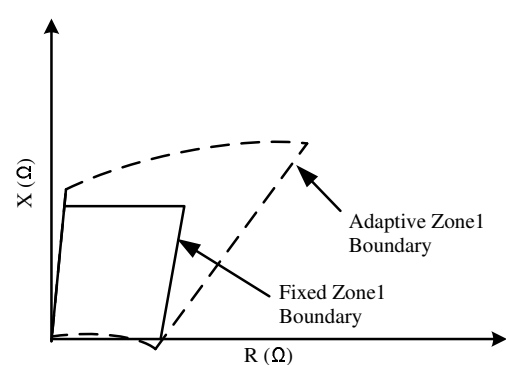

Fig. 7. The two trip boundaries associated in the proposed adaptive relay setting scheme

and derives the protection decision. The timing diagram in Fig. 8 shows the approximate execution time of the proposed scheme. Phasor estimation is performed using 1 cycle Discrete Fourier Transform (DFT) algorithm. The fault classification is accomplished within $4 \mathrm{~ms}$ following fault inception using phase angle relationship between the sequence current components [40]. As usual, the relay takes decision, with the fixed zone-1 setting, within 1 cycle following fault inception [34], [41] and 3 cycles with adaptive zone-1 setting which avoids unintentional backup relay operation.

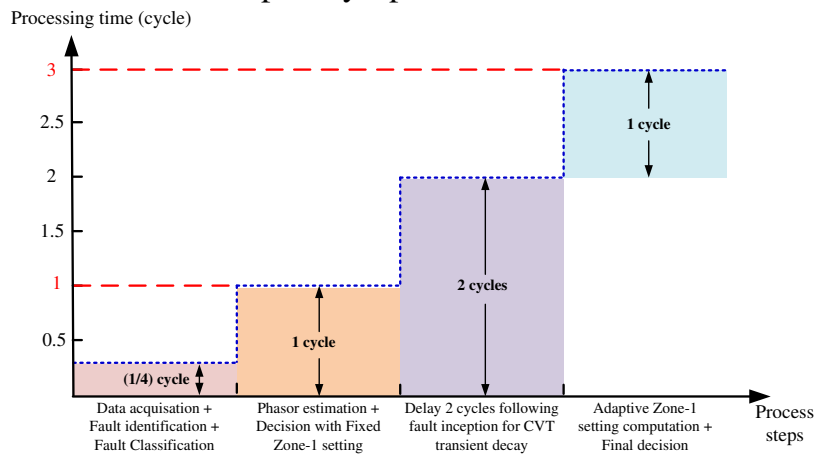

Fig. 8. Timing diagram of the proposed scheme

\section{REsults}

Proposed method is tested for $345 \mathrm{kV}, 60 \mathrm{~Hz}, 39$-bus New England system [42] and the $230 \mathrm{kV}, 60 \mathrm{~Hz}, 12$-bus benchmark system [43] with simulations carried out using EMTDC/PSCAD. Positive-sequence voltage and current are estimated from sampled values using 1-cycle DFT algorithm. The sampling rate for voltage and current measurements is maintained at $1.2 \mathrm{kHz}$. Current transformer (CT) and capacitive voltage transformer (CVT) ratings are mentioned in Appendix II. The results show the application of the proposed scheme to identify zone-1 faults correctly following different structural and operational changes in the system.

\section{A. Case 1: For a Fault following Tie-line Tripping}

The 39-bus New England system of Fig. 9 consists of three interconnected regions. A higher loading condition in region 2 results power withdrawal from other two regions through line 17-16 and line 15-16. Such a stress situation may lead to tripping of these tie lines due to overloading [44]. 


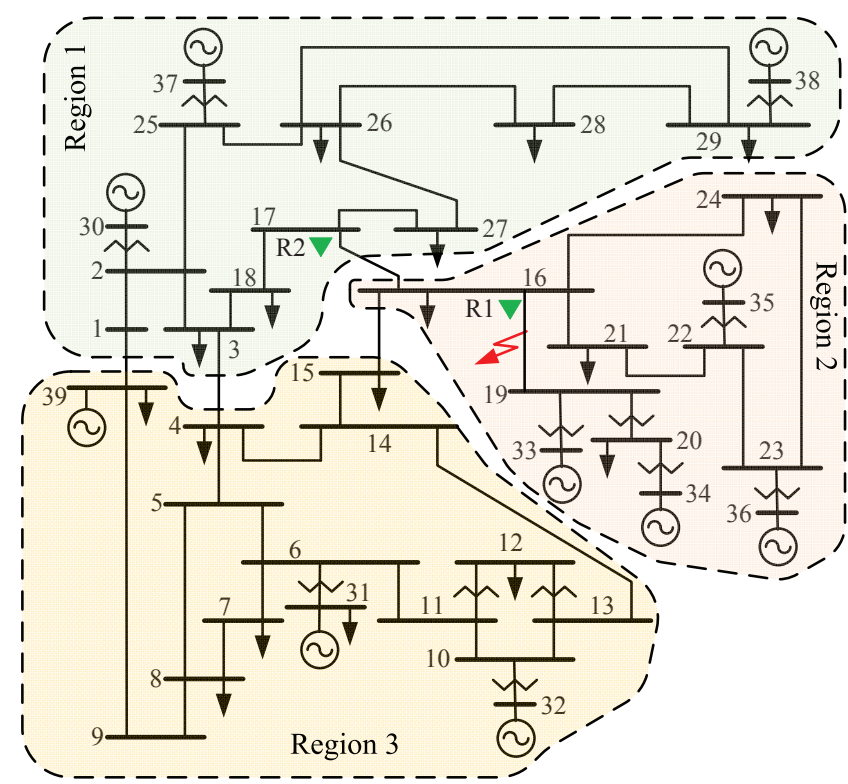

Fig. 9. The 39-bus New England system

Following tripping of line 15-16 due to overload, a line-toground fault in the line 16-19 at a distance of $40 \%$ from bus 16 and with a fault resistance of $90 \Omega$ is not identified in zone1 of relay at bus 16 (R1) as shown in Fig. 10a. Separation of region 3 from region 2 degrades the voltage and power level and changes the local grid equivalent impedance $\left(Z_{L M}\right)$ significantly at bus 16. Calculated value of $Z_{L M}, \rho$ and $\delta$ at bus 16 following tripping of line 15-16 as compared to normal grid condition are provided in Table I. Such changes in the parameters affect the seen impedance of relay R1 for a fault in line 16-19 and the relay is unable to identify the fault in zone-1. This is a clear malfunction of zone-1 of R1. This fault will be identified in zone-2 of R2 at bus 17 as noticed from Fig. 10b. Note that for R2, this change is happening at the remote bus which has no significant affect on it. With the operation by $\mathrm{R} 2$ line 17-16 will trip and result in an unintentional islanding of region $\mathrm{R} 2$.

The adaptive zone- 1 setting is obtained using the parameters calculated after 2 cycles of fault inception. It is seen from the result in Fig. 11 that the apparent impedance enters and settles in the zone-1 with adaptive setting and remains outside the fixed setting. It confirms that the proposed method correctly identify the fault in prescribed zone. This will prevent from unintentional islanding situation created by conventional fixed setting approach for the case as described above.

TABLE I

COMPARISON OF NeTwORK PARAMETERS FOR CASE 1

\begin{tabular}{l|cccc}
\hline \hline \multicolumn{5}{c}{$Z_{1 N R}=139.4 \angle 103^{0} \Omega, Z_{0 N R}=77.13 \angle 43.3^{0} \Omega$} \\
\hline $\begin{array}{l}\text { Without any line } \\
\text { tripping }\end{array}$ & $Z_{1 L M}(\Omega)$ & $Z_{0 L M}(\Omega)$ & $\rho$ & $\delta$ \\
\hline $\begin{array}{l}\text { Following tripping } \\
\text { of line 15-16 }\end{array}$ & $220.7 \angle 128.2^{0}$ & $307.2 \angle 59.9^{0}$ & 1.2 & $30.3^{0}$ \\
\hline
\end{tabular}

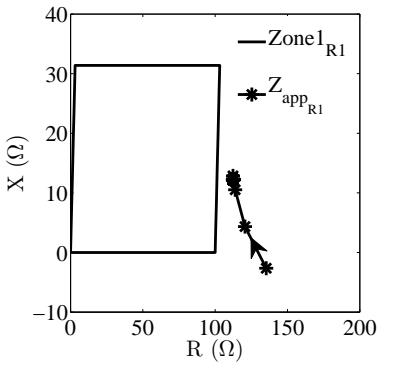

(a)

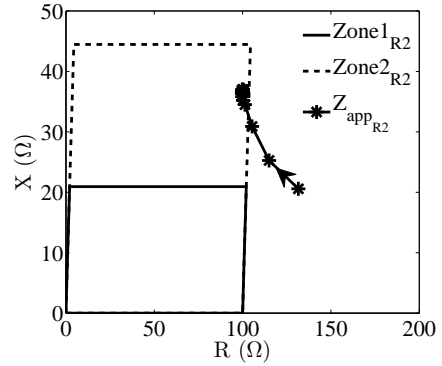

(b)
Fig. 10. Relay performances for a fault following a tie-line tripping (a) for relay R1 at bus 16 and (b) for relay R2 at bus 17

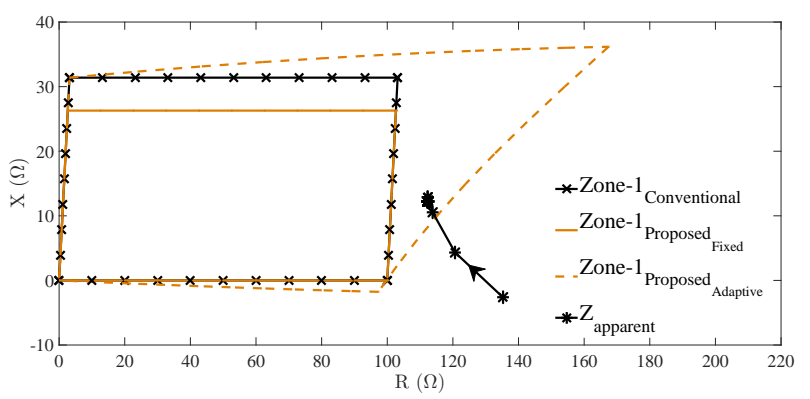

Fig. 11. Performance of proposed method for tie-line tripping

\section{B. Case 2: For a Fault following Bulk Load Switching at a Relay Bus}

Switching of a bulk load at relay bus may also affect apparent impedance calculation by a distance relay. Table II provides the $Z_{L M}, \rho$ and $\delta$ calculated at bus 16 following switching on a higher load at the bus and also for normal load. It is observed that there is a significant change in parameters for higher load. For the case the adaptive setting approach is applied and test result is shown in Fig. 12 for a line-to-ground fault in line 16-19 at a distance of $40 \%$ from bus 16 with a fault resistance of $95 \Omega$ for the higher loading condition. In this case also the apparent impedance seen by relay at bus 16 settles in adaptively set zone- 1 and remains beyond fixed zone-1setting. This clearly shows the advantage of the method compared to conventional approach (It is to be noted that even fixed setting with $80 \%$ cannot see the fault in zone-1 in this case).

TABLE II

Comparison of Network Parameters for Case 2

\begin{tabular}{l|cccc}
\hline \multicolumn{5}{c}{$Z_{1 N R}=57.4 \angle 95^{0} \Omega, Z_{0 N R}=77.3 \angle 43^{0} \Omega$} \\
\hline & $Z_{1 L M}(\Omega)$ & $Z_{0 L M}(\Omega)$ & $\rho$ & $\delta$ \\
\hline $\begin{array}{l}\text { Normal loading } \\
\text { condition }\end{array}$ & $79.7 \angle 106^{0}$ & $114.5 \angle 52.3^{0}$ & 1.005 & $15.9^{0}$ \\
\hline $\begin{array}{l}\text { Following bulk load } \\
\text { switching }\end{array}$ & $97.5 \angle 98.4^{0}$ & $124.41 \angle 41.7^{0}$ & 1.09 & $2.5^{0}$ \\
\hline
\end{tabular}

\section{Case 3: For a Fault following Power Reversal in the Line}

Change in load or generation can alter the power flow direction in a transmission line. Such situation may affect the 


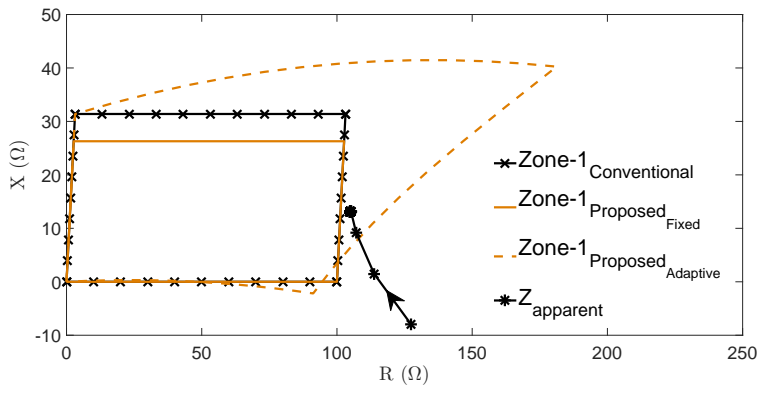

Fig. 12. Performance of proposed method for load switching

apparent impedance calculated by distance relay for a fault in the line. In normal condition the power flows from relay bus to remote bus for the case. Power reversal in the line 16-19 is achieved for a changed loading condition. The change in parameters $\left(Z_{L M}, \rho\right.$ and $\left.\delta\right)$ observed during such situation as compared to normal condition are provided in Table III.

TABLE III

COMPARISON OF NETWORK PARAMETERS FOR CASE 3

\begin{tabular}{l|cccc}
\hline \multicolumn{4}{c}{$Z_{1 N R}=57.4 \angle 95^{0} \Omega, Z_{0 N R}=77.3 \angle 43^{0} \Omega$} \\
\hline & $Z_{1 L M}(\Omega)$ & $Z_{0 L M}(\Omega)$ & $\rho$ & $\delta$ \\
\hline Normal condition & $77.5 \angle 98.4^{0}$ & $124.41 \angle 41.7^{0}$ & 1.09 & $2.5^{0}$ \\
\hline $\begin{array}{l}\text { Following current } \\
\text { reversal }\end{array}$ & $75.4 \angle 96^{0}$ & $75.8 \angle 41.5^{0}$ & 1.11 & $-1.9^{0}$ \\
\hline
\end{tabular}

A line-to-ground fault is created in line 16-19 at a distance of $40 \%$ from bus 16 with a fault resistance of $95 \Omega$ following the reversal of active power flow direction in the protected line. The result by the proposed method is shown in Fig. 13. This shows that the apparent impedance seen by the relay for the situation settles outside the fixed zone-1 setting but remains within the adaptive setting. Thus the method correctly finds the fault in proper zone.

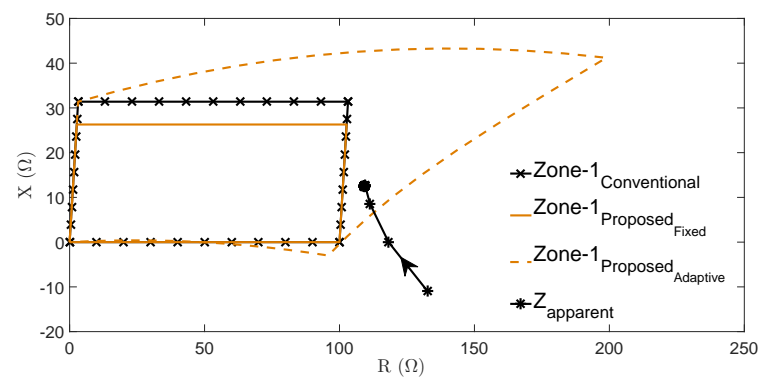

Fig. 13. Performance of proposed method for power reversal

\section{Case 4: For a Fault in the Presence of Series Compensa- tion in the system}

A distance relay protecting a transmission line connected to a series compensated long transmission line may malfunction due to its compensation level. A fixed series compensation system generally consists of a parallel combination of capacitors, metal-oxide varistor (MOV), spark gap and a bypass switch. During a fault in the transmission line, the capacitor in the adjacent line is bypassed by the MOV or spark gap depending on the voltage and energy level across the capacitor and the capacitor is bypassed by the bypass switch during planned operations [45]. Such a situation is simulated for 230 $\mathrm{kV}, 60 \mathrm{~Hz}, 12$-bus power system, a benchmark test system for FACTS devices [43], with a series compensated line connected in the system with $40 \%$ compensation as shown in Fig. 20 in Appendix II. For the protection of line34(1) in the system corresponding equivalent diagram is shown in Fig. 14. A line-to-ground fault in line $\mathrm{MN}$ at a distance of $33 \%$ from $\mathrm{M}$ end, with a fault resistance of $85 \Omega$ in presence of series compensation in the adjacent line, is created. The bypass of series capacitor in the adjacent line changes the network parameters for the relay at $\mathrm{M}$ significantly during a fault in the line and are provided in Table IV. Proposed method is applied and after 2 cycles of fault inception, adaptive setting is obtained. Result in Fig. 15 demonstrates that the apparent impedance settles inside the adaptively set boundary and remains outside the conventional zone- 1 setting. Thus the method has an advantage even in the presence of series compensation in the system.

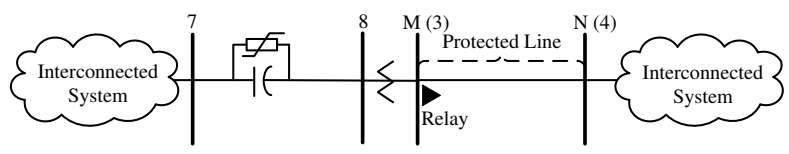

Fig. 14. Equivalent diagram of the 12-bus power system

TABLE IV

COMPARISON OF NeTWORK PARAMETERs FOR CASE 4

\begin{tabular}{l|cccc}
\hline \multicolumn{5}{c}{$Z_{1 N R}=79.13 \angle 50.9^{0} \Omega, Z_{0 N R}=93.12 \angle 70.9^{0} \Omega$} \\
\hline & $Z_{1 L M}(\Omega)$ & $Z_{0 L M}(\Omega)$ & $\rho$ & $\delta$ \\
\hline Without Capacitor bypass & $160.7 \angle 63.5^{0}$ & $228.4 \angle 75.1^{0}$ & 0.92 & $21.3^{0}$ \\
\hline $\begin{array}{l}\text { Capacitor bypassed by } \\
\text { MOV }\end{array}$ & $192.5 \angle 65.9^{0}$ & $270.3 \angle 76.1^{0}$ & 0.91 & $23.7^{0}$ \\
\hline
\end{tabular}

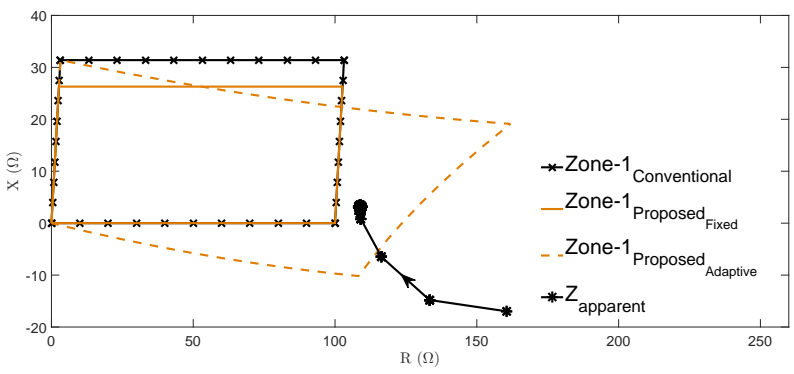

Fig. 15. Performance of proposed method in presence of series compensation

\section{E. Case 5: For a Fault with a Wind Farm in the System}

A wind farm is generally consist of several units of generators connected in parallel. At a instant, number of units may not be in operation due to maintanance or wind speed. Such situation may affect the distance relay protecting the 
transmission line connecting the farm. A case is simulated in the 12-bus power system with wind farm connected at bus 12 (shown in Fig. 20 in Appendix II) [46]. The equivalent model of the test system is shown in Fig. 16. The wind farm consists of nine units of 2.25 MVA each. At an instant of

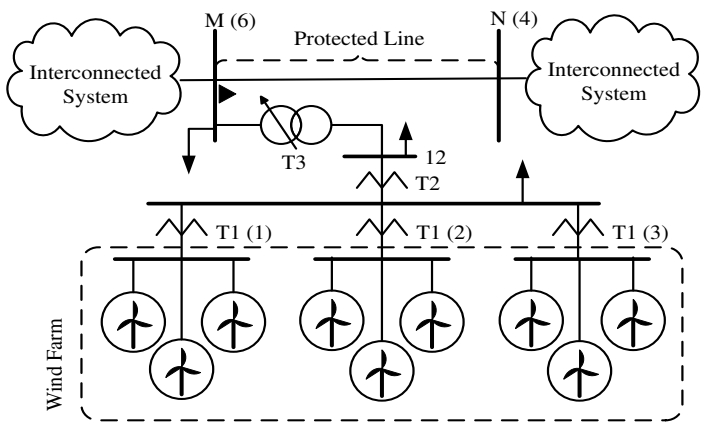

Fig. 16. Equivalent model of 12-bus system with wind farm

time, only 3 units were in operation and thereby the local grid equivalent impedance becomes significantly high as in Table V. At the situation a line-to-ground fault is created in the line $\mathrm{MN}$ at a distance of $50 \%$ from bus $\mathrm{M}$ and $R_{F}=90 \Omega$. The performance of the proposed method is shown in Fig. 17. It is seen that the apparent impedance settles inside the adaptively set boundary and is outside the fixed setting. This clearly shows the advantage of the method for line connecting wind farm where variation in no. of units in operation is common.

TABLE V

COMParison of Network Parameters for CASE 5

\begin{tabular}{l|cccc}
\hline \multicolumn{5}{c}{$Z_{1 N R}=86.82 \angle 57.09^{0}, Z_{0 N R}=170.05 \angle 40.9^{0}$} \\
\hline Prefault condition & $Z_{1 L M}(\Omega)$ & $Z_{0 L M}(\Omega)$ & $\rho$ & $\delta$ \\
\hline 9 Units in Operation & $164.97 \angle 81.2^{0}$ & $59.8 \angle 79.29^{0}$ & 0.96 & $28.36^{0}$ \\
\hline 3 Units in Operation & $368.06 \angle 61.3^{0}$ & $157.5 \angle 71.5^{0}$ & 1.12 & $15.67^{0}$ \\
\hline
\end{tabular}

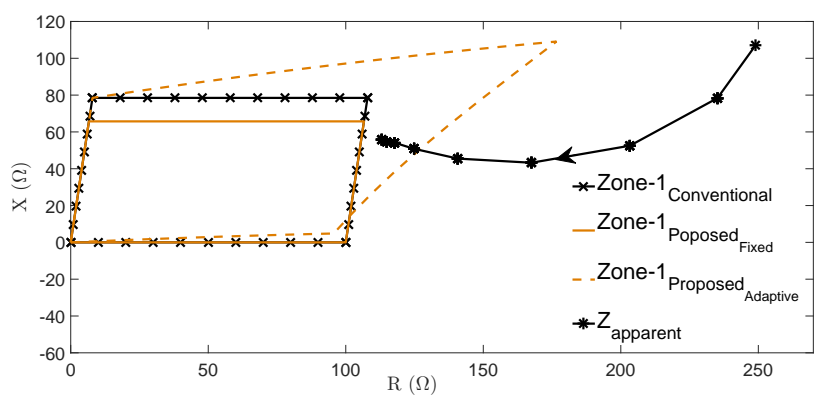

Fig. 17. Performance of proposed method in the presence of wind farm

\section{F. Case 6: Improved performance of PUTT scheme with proposed method}

Permissive underreaching transfer trip (PUTT) scheme is used to accelerate the tripping operation for fault in the protected line using other end relay decision [47], [48]. Due to structural or operational changes in the system, this scheme may also fail to detect fault in some situations. Such a fault situation is simulated in 39-bus New England system. Following tripping of line 17-16, a line-to-ground fault is created in line 16-19 at a distance of $15 \%$ from bus 16 , with a fault resistance of $95 \Omega$. The equivalent diagram of the situation is shown in Fig. 18. In this case, relay $R_{M}$ is unable

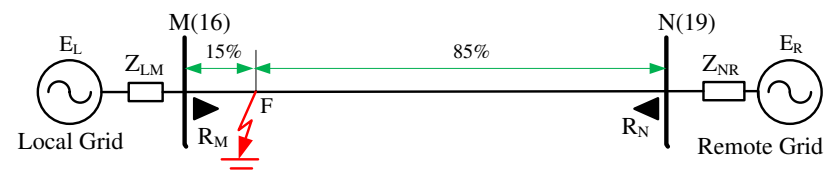

Fig. 18. Equivalent diagram of the 39-bus New England system for the fault situation

to identify the fault with conventional zone-1 setting with a fault resistance coverage of $100 \Omega$ because of increment in local grid equivalent impedance $\left(Z_{L M}\right)$. On the other hand, as usual, relay $R_{N}$ detects the fault in zone- 2 correctly. The dynamic performances of both relays are shown in Fig. 19. Thus, as seen from Fig. 19, PUTT scheme fails to perform correctly due to non-detection of fault by relay $R_{M}$ with its conventional zone-1 setting [47]. Result in Fig. 19 shows that relay $R_{M}$ can identify the fault correctly in zone-1 with its adaptive setting and can send the decision to relay $R_{N}$ to accelerate its zone-2 operation. This shows a clear advantage with proposed method while applied in PUTT scheme.

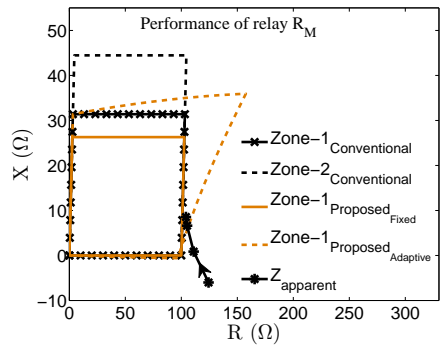

(a)

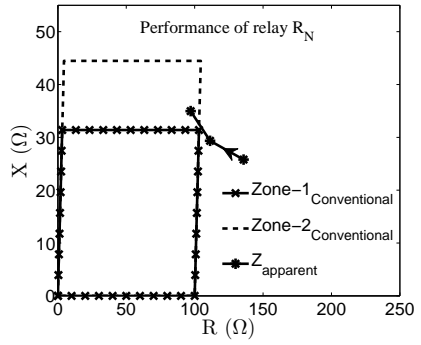

(b)
Fig. 19. Application of proposed method in improving PUTT scheme

\section{CONCLUSION}

The structural and operational changes in power system affect the impedance calculated by distance relay during fault. The high resistance fault during such situations may not be identified in prescribed zone with fixed setting distance relay. An adaptive relay setting scheme is proposed to prevent zone1 malfunction for faults following such changes in the system. Proposed scheme consists of two settings; one fixed and the other adaptive one with a delay. The method uses local data to calculate the parameters for the adaptive setting. Fixed setting maintains the instantaneous tripping requirement for any fault within its reach. On the other hand, following any structural or operational change in the system, a fault in zone1 is identified within the adaptive setting accurately after 2 cycles of fault inception even if fixed setting approach fails. Such a strategy overcomes the delayed response by the backup protection scheme for zone-1 fault during such situations. 
The improved performance of the method is demonstrated for different situations such as tie-line tripping, bulk load switching, power reversal, presence of series compensation and with wind power integration. This method is found to be advantageous to PUTT scheme following such a changed situation in the system.

\section{APPENDIX I}

For a phase A-to-ground fault at $\mathrm{F}$ in Fig. 2, the sequence currents through the fault resistance become

$$
I_{1 F}=I_{2 F}=I_{0 F}=\frac{V_{A F_{p r e}}}{\left(C_{e q}+C_{R_{F}}\right)}
$$

where $V_{A F_{p r e}}$ is the prefault phase A voltage at F. $C_{e q}$ and $C_{R_{F}}$ are the equivalent sum of the sequence impedances and fault resistance of the network in Fig. 5 respectively and are defined as

$$
\begin{gathered}
C_{e q}=\frac{2\left(Z_{1 L M}+x Z_{1 L}\right)\left(Z_{1 N R}+(1-x) Z_{1 L}\right)}{\left(Z_{1 L M}+x Z_{1 L}\right)+\left(Z_{1 N R}+(1-x) Z_{1 L}\right)} \\
+\frac{\left(Z_{0 L M}+x Z_{0 L}\right)\left(Z_{0 N R}+(1-x) Z_{0 L}\right)}{\left(Z_{0 L M}+x Z_{0 L}\right)+\left(Z_{0 N R}+(1-x) Z_{0 L}\right)} \\
C_{R_{F}}=3 R_{F}
\end{gathered}
$$

The distribution of sequence currents at bus $M$ can be expressed as

$$
\begin{gathered}
I_{1 M}=I_{2 M}=C_{12} I_{1 F} \\
I_{0 M}=C_{0} I_{0 F}
\end{gathered}
$$

The current distribution factors involved in (18) and (19) are defined as

$$
\begin{gathered}
C_{12}=\frac{\left(Z_{1 N R}+(1-x) Z_{1 L}\right)}{\left(Z_{1 N R}+(1-x) Z_{1 L}\right)+\left(Z_{1 L M}+x Z_{1 L}\right)} \\
C_{0}=\frac{\left(Z_{0 N R}+(1-x) Z_{0 L}\right)}{\left(Z_{0 N R}+(1-x) Z_{0 L}\right)+\left(Z_{0 L M}+x Z_{0 L}\right)}
\end{gathered}
$$

The phase A apparent impedance calculated by distance relay at bus $\mathrm{M}$ during a phase $\mathrm{A}$ to ground fault is expressed as

$$
Z_{a p p}=\frac{V_{A M}}{I_{A M}+K_{0} I_{0 M}}
$$

where $V_{A M}$ and $I_{A M}$ are the voltage and current at phase A at bus $\mathrm{M}$ during fault. The zero sequence compensating factor $\left(K_{0}\right)$ is defined as

$$
K_{0}=\frac{Z_{0 L}-Z_{1 L}}{Z_{1 L}}
$$

Substituting the sequence current components and prefault voltage in (22), $Z_{a p p}$ can be expressed as

$$
Z_{a p p}=x Z_{1 L}+\frac{C_{R_{F}}}{\left(C_{e q}+C_{R_{F}}\right) C_{\rho \delta}+2 C_{12}+C_{0}\left(1+K_{0}\right)}
$$

where $C_{\rho \delta}$ is defined as

$$
C_{\rho \delta}=\frac{\left(1-\rho e^{-j \delta}\right)}{\left(Z_{1 N R}+(1-x) Z_{1 L}\right)+\left(Z_{1 L M}+x Z_{1 L}\right) \rho e^{-j \delta}}
$$

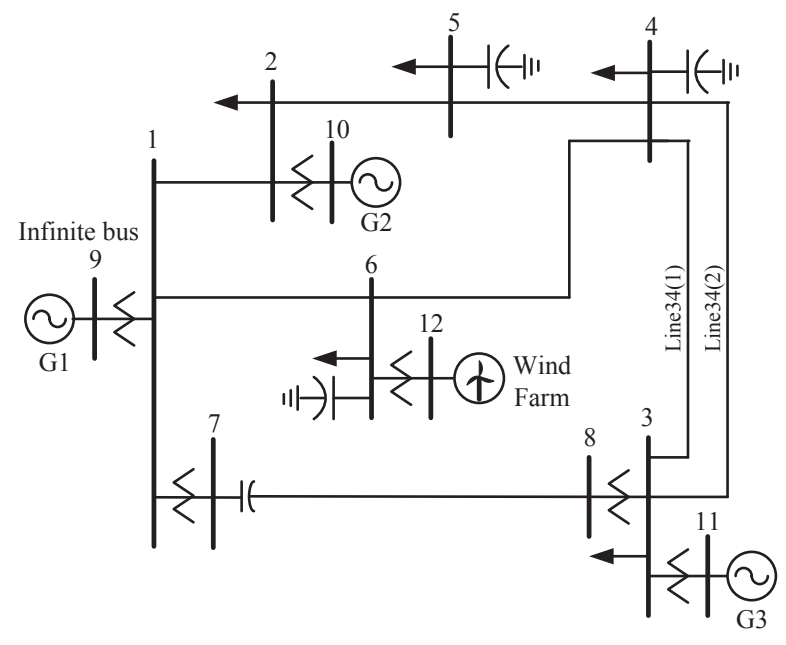

Fig. 20. The 12-bus power system

\section{APPENDIX II \\ SYSTEM DATA}

\begin{tabular}{|c|c|c|}
\hline \multicolumn{3}{|c|}{ For $345 \mathrm{kV}, 60 \mathrm{~Hz}, 39$-bus New England system: } \\
\hline Current Transformer & \multicolumn{2}{|c|}{ Capacitive Voltage Transformer } \\
\hline Ratio : $\quad 300: 5$ & Ratio & $: \quad 3000: 1$ \\
\hline Class : $\quad 5 \mathrm{P} 40$ & Total Capacitance & : $\quad 4400 \mathrm{pF}$ \\
\hline \multirow[t]{2}{*}{ Core : $\quad$ Selectron 53} & Intermediate Voltage & $: \quad 12.7 \mathrm{kV}$ \\
\hline & Class & $: 3 \mathrm{P}$ \\
\hline \multicolumn{3}{|c|}{ For $230 \mathrm{kV}, 60 \mathrm{~Hz}$ 12-bus system: } \\
\hline Current Transformer & \multicolumn{2}{|c|}{ Capacitive Voltage Transformer } \\
\hline Ratio : $\quad 1000: 5$ & Ratio & $2000: 1$ \\
\hline Class : $\quad 5 \mathrm{P} 40$ & Total Capacitance & : $\quad 4400 \mathrm{pF}$ \\
\hline \multirow[t]{2}{*}{ Core : $\quad$ Selectron 53} & Intermediate Voltage & $: \quad 12.7 \mathrm{kV}$ \\
\hline & Class & $: \quad 3 \mathrm{P}$ \\
\hline
\end{tabular}

The transmission line, transformer, generator and load data for 39 bus New England system used in simulation are as in [42] with little modification on line lengths and loading conditions to satisfy the requirements for different situations.

The transmission line, transformer and generator with exciter data for the 12-bus system are same as in [43].

TABLE VI

WIND FARM DATA

\begin{tabular}{l|l}
\hline \hline No. of Units & 9 \\
\hline Generating Unit & SCIG, $415 \mathrm{~V}, 2.25 \mathrm{MVA}, 60 \mathrm{~Hz}$ \\
\hline Transformers & T1: $415 \mathrm{~V} / 22 \mathrm{kV}, 10 \mathrm{MVA}, 60 \mathrm{~Hz}$ \\
& T2: $22 \mathrm{kV} / 110 \mathrm{kV}, 50 \mathrm{MVA}, 60 \mathrm{~Hz}$ \\
& T3: $110 \mathrm{kV} / 230 \mathrm{kV}, 100 \mathrm{MVA}, 60 \mathrm{~Hz}$ \\
\hline
\end{tabular}

TABLE VII

DATA FOR INSTRUMENT TRANSFORMERS

\section{ACKNOWLEDGMENT}

The authors are thankful to Department of Science and Technology (DST), New Delhi, India, for sponsoring the Indo-UK joint project, "Advanced communication 
TABLE VIII

SERIES COMPENSATION DATA

\begin{tabular}{lll}
\hline Capacitor & $:$ & $81.1 \mu \mathrm{F}$ \\
MOV Characteristic & $:$ & ASEA XAP-A \\
MOV Reference Voltage & $:$ & $25 \mathrm{kV}$ \\
Spark-gap Type & $:$ & Switch Triggered by Energy Threshold \\
Triggering Energy Threshold & $:$ & $0.75 \mathrm{MJ}$ \\
\hline
\end{tabular}

and control for the prevention of blackouts (ACCEPT)DST/RCUK/SEGES/2012/02(G)", through which the research was conducted.

\section{REFERENCES}

[1] M. Eremia and M. Shahidehpour, Major Grid Blackouts: Analysis, Classification, and Prevention. WileyIEEE Press, 2013, pp. 789-863. [Online]. Available: http://ieeexplore.ieee.org/xpl/articleDetails.jsp?arnumber=6482751

[2] S. Horowitz and A. Phadke, "Blackouts and relaying considerations relaying philosophies and the future of relay systems," Power and Energy Magazine, IEEE, vol. 4, no. 5, pp. 60-67, Sept 2006.

[3] A. Atputharajah and T. Saha, "Power system blackouts-literature review," in Proc. Int. Conf. Ind. Inf. Syst., 2009, pp. 460-465.

[4] M. Tasdighi and M. Kezunovic, "Automated review of distance relay settings adequacy after the network topology changes," IEEE Trans. Power Del., vol. 31, no. 4, pp. 1873-1881, Aug 2016.

[5] M. Kezunovic, T. Popovic, G. Gurrala, P. Dehghanian, A. Esmaeilian, and M. Tasdighi, "Reliable implementation of robust adaptive topology control," in Proc. International Conference on System Sciences (HICSS), Jan 2014, pp. 2493-2502.

[6] I. Abdulhadi, A. Dysko, and G. Burt, "Reachability analysis for the verification of adaptive protection setting selection logic," IEEE Trans. Power Del., vol. 29, no. 5, pp. 2206-2214, Oct 2014.

[7] A. K. Pradhan and G. Joos, "Adaptive distance relay setting for lines connecting wind farms," IEEE Trans. Energy Conv, vol. 22, no. 1, pp. 206-213, March 2007.

[8] D. Kang and R. Gokaraju, "A new method for blocking third zone distance relays during stable power swings," IEEE Trans. Power Del., vol. PP, no. 99, pp. 1-1, 2016.

[9] K. Seethalekshmi, S. Singh, and S. Srivastava, "A classification approach using support vector machines to prevent distance relay maloperation under power swing and voltage instability," IEEE Trans. Power Del., vol. 27, no. 3, pp. 1124-1133, July 2012.

[10] S. A. Soman, T. B. Nguyen, M. A. Pai, and R. Vaidyanathan, "Analysis of angle stability problems: a transmission protection systems perspective," IEEE Trans. Power Del., vol. 19, no. 3, pp. 1024-1033, July 2004.

[11] R. Vaidyanathan and S. A. Soman, "Distance relay coordination considering power swings," in Proc. Int. Conf. Power Syst. Commun. Syst. Infrastructures for Future, 2002.

[12] P. Kundu and A. K. Pradhan, "Enhanced protection security using the system integrity protection scheme (SIPS)," IEEE Trans. Power Del., vol. 31, no. 1, pp. 228-235, Feb 2016.

[13] Z. Li, X. Lin, H. Weng, and Z. Bo, "Efforts on improving the performance of superimposed-based distance protection," IEEE Trans. Power Del., vol. 27, no. 1, pp. 186-194, Jan 2012.

[14] A. Jongepier and L. van der Sluis, "Adaptive distance protection of a double-circuit line," IEEE Trans. Power Del., vol. 9, no. 3, pp. 12891297, Jul 1994.

[15] E. Orduna, F. Garces, and E. Handschin, "Algorithmic-knowledge-based adaptive coordination in transmission protection," IEEE Trans. Power Del., vol. 18, no. 1, pp. 61-65, Jan 2003.

[16] B. Stedall, P. Moore, A. Johns, J. Goody, and M. Burt, "An investigation into the use of adaptive setting techniques for improved distance backup protection," IEEE Trans. Power Del., vol. 11, no. 2, pp. 757-762, Apr 1996.

[17] Y. Xia, K. Li, and A. David, "Adaptive relay setting for stand-alone digital distance protection," IEEE Trans. Power Del., vol. 9, no. 1, pp. 480-491, Jan 1994.

[18] K. Li, L. Lai, and A. David, "Stand alone intelligent digital distance relay," IEEE Trans. Power Systems, vol. 15, no. 1, pp. 137-142, Feb 2000.
[19] J. Upendar, C. Gupta, and G. Singh, "Comprehensive adaptive distance relaying scheme for parallel transmission lines," IEEE Trans. Power Del., vol. 26, no. 2, pp. 1039-1052, April 2011.

[20] V. Makwana and B. Bhalja, "A new digital distance relaying scheme for compensation of high-resistance faults on transmission line," IEEE Trans. Power Delivery, vol. 27, no. 4, pp. 2133-2140, Oct 2012.

[21] J. Ma, W. Ma, Y. Qiu, and J. Thorp, "An adaptive distance protection scheme based on the voltage drop equation," IEEE Trans. Power Del., vol. 30, no. 4, pp. 1931-1940, Aug 2015.

[22] Q. Liu, S. Huang, H. Liu, and W. Liu, "Adaptive impedance relay with composite polarizing voltage against fault resistance," IEEE Trans. Power Delivery, vol. 23, no. 2, pp. 586-592, April 2008.

[23] Z. Xu, S. Jiang, Q. Yang, and T. Bi, "Ground distance relaying algorithm for high resistance fault," IET Generation, Transmission Distribution, vol. 4, no. 1, pp. 27-35, January 2010.

[24] A. Filomena, R. Salim, M. Resener, and A. Bretas, "Ground distance relaying with fault-resistance compensation for unbalanced systems," IEEE Trans. Power Delivery, vol. 23, no. 3, pp. 1319-1326, July 2008.

[25] L. Yan, C. Deshu, Y. Xianggen, and Z. Zhe, "Research of one new adaptive mho relay," in Proc. International Conference on Power System Technology, vol. 4, 2002, pp. 2604-2607.

[26] M. J. Thompson and D. L. Heidfeld, "Transmission line setting calculations beyond the cookbook," in Proc. 68th Annual Conference for Protective Relay Engineers, March 2015, pp. 1-16.

[27] M. Thompson and A. Somani, "A tutorial on calculating source impedance ratios for determining line length," in Proc. 68th Annual Conference for Protective Relay Engineers, March 2015, pp. 833-841.

[28] D. Costello and K. Zimmerman, "CVT transients revisited distance, directional overcurrent, and communications-assisted tripping concerns," in Proc. 65th Annual Conference for Protective Relay Engineers, April 2012, pp. 1-12.

[29] S. Zubi and P. Balcerek, "Impedance surfing method for CVT transient mitigation," in 2016 10th International Conference on Compatibility, Power Electronics and Power Engineering (CPE-POWERENG), June 2016, pp. 64-69.

[30] S. Automation and P. Division, "Rel 512 setting example for short lines," ABB, Tech. Rep., [Online]. Available: http://library.e.abb.com/public/6d1ce09322b71f6985256f34004e27d9/AN60L-00.pdf.

[31] J. G. Andrichak and G. Alexander, "Distance relay fundamentals," GE Power Management, Tech. Rep., [Online]. Available: http://store.gedigitalenergy.com/faq/documents/alps/ger-3966.pdf.

[32] G. E. Alexander, J. G. Andrichak, and W. Z. Tyska, "Relaying short lines," GE Power Management, Tech. Rep., [Online]. Available: http://store.gedigitalenergy.com/faq/documents/alps/ger-3735.pdf.

[33] Siemens, "Distance protection relay for transmission lines," Tech. Rep. 1999, [Online]. Available: ftp://ftp.so-cdu.ru/RZA/Siemens/SIPROTEC

[34] Alstom, "Network protection and automation guide," Tech. Rep. 978-0-9568678-0-3, May 2011, [Online]. Available: ftp://196.14.46.153/pub/ProtectionControl/Relays/NPRAG/NPAG[1].pdf

[35] C. international des grands réseaux électriques. Comité d'études B5, Modern distance protection: functions and applications. CIGRE, 2008. [Online]. Available: https://books.google.co.in/books?id=vlaQwAACAAJ

[36] G. Benmouyal and J. Roberts, "Superimposed quantities: Their true nature and application in relays," in Proc. 26th Annual Western Protective Relay Conference, October 1999, pp. 1-18.

[37] P. M. Anderson, Power system protection. Wiley-IEEE Press, 1998, pp. 394-400.

[38] B. Kasztenny, D. Sharples, V. Asaro, and M. Pozzouli, "Distance relays and capacitive voltage transformers-balance speed and transient overreach," in 53rd Annual conference for Protective Relay Engineers. GE Power Management, April 2000, [Online]. Available: http://store.gedigitalenergy.com/faq/documents/alps/ger-3986.pdf.

[39] G. A. Franklin and R. Horton, "Determining distance relay zone-1 reach settings to prevent CCVT transient overreach," in Proc. IEEE Southeastcon, March 2011, pp. 1-5.

[40] B. Kasztenny, B. Campbell, and J. Mazereeuw, "Phase selection for single-pole tripping weak infeed conditions and cross-country faults," GE Power Management, Tech. Rep., October 2000, [Online]. http://store.gedigitalenergy.com/FAQ/Documents/Alps/GER-3997.pdf.

[41] REL 150/REZ 1 Distance relay, ABB, June 1999, [Online]. Available: https://library.e.abb.com/public/ab55ce627ea79f7fc1256fbf00778f68/ 1MRK506008-BEN_en_REL_150__REZ_1_Distance_relay.pdf.

[42] I. Hiskens, "IEEE PES task force on benchmark systems for stability controls," Tech. Rep., November 2013, [Online]. Available: 
[43] S. Jiang, U. Annakkage, and A. Gole, "A platform for validation of FACTS models," IEEE Trans. Power Del., vol. 21, no. 1, pp. 484-491, Jan 2006.

\section{BIOGRAPHIES}
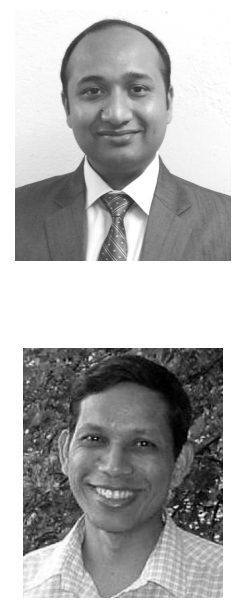

Subhadeep Paladhi (S'14) received the B.E. degree in Electrical Engineering from University of Burdwan, India, in 2013 and M. Tech. degree in Power Systems from National Institute of Technology Calicut, India in 2015. He is currently working toward the $\mathrm{PhD}$ degree in Electrical Engineering at Indian Institute of Technology, Kharagpur, India.

His current research interests include Power System Protection.

Ashok Kumar Pradhan (SM'10, M'94) received the Ph.D. degree in Electrical Engineering from Sambalpur University, Sambalpur, India, in 2001.

$\mathrm{He}$ has been with the Department of Electrical Engineering, Indian Institute of Technology, Kharagpur, India, since 2002, where he is currently a Professor. He served at the Department of Electrical Engineering, VSS University of Technology, Burla, India from 1992-2002. His research interests include power system relaying and monitoring.

Prof. Pradhan is a Fellow of Indian National Academy of Engineering (INAE) India.
[44] Powergrid, "Report of the enquiry committee on grid disturbance in northern region on 30th July 2012 and in northern, eastern and north-eastern region on 31st July 2012," New Delhi, India, Tech. Rep., Aug 2012, [Online]. Available: http://www.powermin.nic.in/pdf/GRID_ENQ_REP_16_8_12.pdf.

[45] J. Miller, M. Brunet-Watson, and J. Leighfield, "Review of series compensation for transmission lines," PSC North America, Tech. Rep., May 2014.

[46] A. Adamczyk, M. Altin, O. Goksu, R. Teodorescu, and F. Iov, "Generic 12-bus test system for wind power integration studies," in 15th European Conference on Power Electronics and Applications (EPE), Sept 2013, pp. 1-6.

[47] H. J. A. Ferrer(editor) and E. O. SchweitzerIII(editor), Modern solutions for protection, control, and monitoring of electric power systems. Pullman, Wash. (2350 NE Hopkins Court, Pullman, WA 99163 USA) Schweitzer Engineering Laboratories, 2010, pp. 79-83.

[48] S. H. Horowitz and A. G. Phadke, Power system relaying. John Wiley \& Sons, 2008, pp. 147-148. 